INTERNATIONAL JOURNAL OF SCIENTIFIC RESEARCH

\title{
AGE AND GENDER PREDILECTION OF PLASMA C-REACTIVE PROTEIN LEVELS ON MORTALITY IN FIRST EVER ACUTE ISCHEMIC STROKE
}

\begin{tabular}{ll}
\hline Medicine & \\
Bharat L. Konin & Professor Dept of Internal Medicine, M.R.Medical College,Gulburga. \\
\hline Shiney Aggarwal & Post Graduate Dept of Internal Medicine, M.R.Medical College,Gulburga. \\
\hline $\begin{array}{l}\text { Swaraj S. } \\
\text { Waddankeri* }\end{array}$ & $\begin{array}{l}\text { Associate Professor Dept of Internal Medicine, M.R.Medical College, Gulburga. } \\
\text { *Corresponding Author }\end{array}$
\end{tabular}

\section{ABSTRACT}

Background and Purpose: The measurement of markers of inflammation or thrombosis has been proposed as a method to improve the prediction of risk in patients with vascular disease. The role of C-reactive protein (CRP) as a novel plasma marker of atherothrombotic disease is currently under investigation. We related age and gender predilection of plasma CRP levels to first ever ischemic stroke and its role on mortality. Methods: Sixty patients with either hypertension or diabetes or both or none without thrombolysis with first ever acute ischemic stroke patients were examined. CT scan of brain was done after 24 hours of onset of symptoms to confirm the diagnosis. Plasma CRP level was determined after $12-72$ hours range after the onset of symptoms in all CT confirmed ischemic stroke patients. This clinical study was done during June 2018 to January 2020. CRP was randomly measured in 60 age and sex matched individuals admitted in other wards of the hospital matched in all possible criteria expect the disease under study as a control group. Results: The CRP concentration in ischemic strokes is independent of infarction site, the value was more between 51-70 years of age group and almost equal in both gender. 54 of the 60 ischemic strokes studied had CRP value $>6 \mathrm{mg} / 1$ and only 6 patients had $<6 \mathrm{mg} / 1(\mathrm{p}<0.001)$, chi square test value is $\mathrm{c}^{2}=73.65$ which is statistically significant. Only 7 of the 60 control group had CRP $>6 \mathrm{mg} / 1$. Conclusion: In this study mean C-Reactive protein levels were significantly higher in patients with ischemic stroke when compared to controls. Creactive protein level increases as age advances. C-reactive protein is a better prognostic marker with no gender predilection and not a mortality predictor.

\section{KEYWORDS}

C-Reactive Protein; Ischemic Stroke.

\section{MATERIALS AND METHODS}

This study "Age and Gender Predilection of Plasma C Reactive Protein levels on Mortality in first ever acute ischemic stroke" was carried out in Basaveshwar Teaching \& General Hospital, Gulbarga during the period from June 2018 to January 2020

The study was undertaken with the following aims:

1) To observe Plasma CRP levels in acute ischemic stroke.

2) To evaluate the role of age and gender predilection of CRP on mortality in first ever acute ischemic stroke.

Selection of Patients: This study was conducted in patients admitted with first ever attack of ischemic stroke to intensive care unit or acute medical ward in Department of Medicine, Basaveshwar Teaching \& General Hospital, Gulbarga.

Period of Study: From June 2018 to January 2020.

Sample Size: 250 patients admitted with stroke (CT proved) were selected for the study, of this 200 patients had thrombotic stroke. Out of this 60 were selected after exclusion of patients having heart disease, infection, tuberculosis, malignancies anywhere in the body, previous history of stroke, TIA and other factors known to alter CRP value as the study group. 60 age and sex matched control subjects were selected from patients in other wards matched in every possible aspect except for the disease under study.

Study Group: Of 200 stroke patients, 60 were selected as the study group strictly adhering to the inclusion criteria.

\section{Inclusion criteria:}

1) Age group 20-80years

2) Patients with either or both type 2 diabetes mellitus and hypertension or none.

3) Ischemia proved by CT scan brain, in all cases of the study.

Exclusion Criteria:

1) Age $<20$ years and $>80$ years.

2) Patients with history of heart disease - any valvular heart disease, myocardial infarction.

3) Patients with previous history of stroke or TIA.

4) Patients with collagen vascular diseases, active tuberculosis, arteritis.

5) Patients with hemorrhagic stroke, tumor, subarachnoid

\section{hemorrhage.}

6) Patients with head injury within past 3 months.

7) CT negative stroke.

8) Patients with meningitis, brain abscess or any chronic infection that affect CRP value.

\section{Study Protocol:}

Clinical history was taken from either the patient or his/ her relatives or attender, while taking history importance was given regarding presence or absence of vomiting, headache and convulsions. Past history of hypertension, diabetes, CAD, RHD, TIA, collagen diseases, meningitis, tuberculosis, endocrine disorders and congenital disorders were taken. Personal history regarding dietary habits, smoking, alcohol consumption and tobacco chewing were noted. NIH stroke scale was assessed in all patients to assess the neurological disability and its prognosis. Detailed neurological examination was done based on proforma. All other systems like cardiovascular system, gastrointestinal system, and respiratory system were examined in detail. Detailed investigations including blood hemoglobin, TLC, DC, urine routine, FBS, lipid profile, ECG, chest X-ray, 2D-ECHO were done,CT scan after 24 hours after onset of symptoms and C-reactive protein estimation was done anytime between 12-72 hours of symptom onset.

\section{CT Scanning:}

In all cases, only plain CT was done. The CT scan is done after 24 hours of stroke.

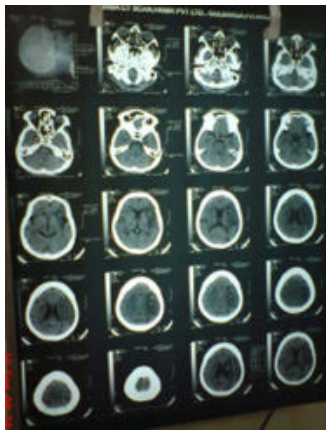

\section{Figure 1}

Figure $1 \mathrm{Ct}$ Scan Brain Showing Large infarct $(7 \mathrm{x} 4 \mathrm{~cm})$ in the left Parietal Cortex 


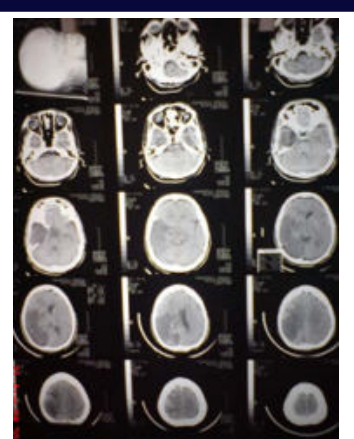

Figure 2

Figure 2 CT Scan Brain Showing Infarct in the Left Temporoparietal Region

\section{OBSERVATIONS}

There were 250 cases of first episode stroke in Basaveshwar Teaching and General Hospital during the period of June 2018 to January 2020.

Of those 200 cases were CT proved ischemic stroke. Of those 60 cases were studied after excluding the patients using the exclusion criteria.

60 age and sex matched controls were studied as the control group.

Table-1: Type of Stroke CT Evaluated $(\mathrm{N}=\mathbf{2 5 0})$

\begin{tabular}{|c|c|c|}
\hline Type of stroke & No. of cases & Percentage \\
\hline Ischemic stroke & 200 & $80 \%$ \\
\hline Hemorrhagic & 50 & $20 \%$ \\
\hline Total & 250 & $100 \%$ \\
\hline
\end{tabular}

The above table shows that $80 \%$ of cases were ischemic strokes while only $20 \%$ constituted hemorrhagic stroke which included intracerebral and sub Arachnoid hemorrhage.

Table-2 : Sex Distribution in Study Group $(\mathrm{N}=60)$

\begin{tabular}{|c|c|c|}
\hline Sex & Total & Percentage \\
\hline Males & 37 & $61.6 \%$ \\
\hline Females & 23 & $38.4 \%$ \\
\hline
\end{tabular}

Table 2 shows sex distribution of the study group where $61.6 \%$ were males and $38.4 \%$ were females.

Table 3 Age and sex distribution in study group $(\mathrm{N}=60)$

\begin{tabular}{|l|l|l|l|l|l|l|}
\hline \multirow{2}{*}{$\begin{array}{l}\text { Age in } \\
\text { years }\end{array}$} & \multicolumn{3}{|l|}{ No. of patients } & Total & Percentage \\
\cline { 2 - 7 } & Male & Percentage & Female & Percentage & & \\
\hline $21-30$ & 0 & 0 & 0 & 0 & 0 & 0 \\
\hline $31-40$ & 4 & 10.8 & 0 & 0 & 4 & 6.6 \\
\hline $41-50$ & 6 & 16.2 & 6 & 28.1 & 12 & 20.0 \\
\hline $51-60$ & 8 & 21.6 & 4 & 17.4 & 12 & 20.0 \\
\hline $61-70$ & 10 & 27.0 & 8 & 37.8 & 18 & 30.0 \\
\hline $71-80$ & 9 & 24.4 & 5 & 21.7 & 14 & 23.4 \\
\hline
\end{tabular}

Table 3 shows maximum thrombotic stroke patients were in the age group of $61-70$ constituting $30 \%$ of the study population. Young stroke (age $<40$ years) were found only in $6.6 \%$ (Ratio of $1: 15$ ) of cases all of whom were males. Women $<50$ years accounted only for 6 cases i.e. $10 \%$ of the total cases

Table 4 : Age and Sex Distribution of Control Group $(N=60)$

\begin{tabular}{|c|c|c|c|c|c|c|}
\hline $\begin{array}{c}\text { Age in } \\
\text { years }\end{array}$ & \multicolumn{4}{|c|}{ No. of patients } & Total & Percentage \\
\cline { 2 - 5 } & Male & Percentage & Female & Percentage & & \\
\hline $21-30$ & 0 & 0 & 0 & 0 & 0 & 0 \\
\hline $31-40$ & 4 & 10.8 & 0 & 0 & 4 & 6.6 \\
\hline $41-50$ & 6 & 16.2 & 6 & 28.1 & 12 & 20.0 \\
\hline $51-60$ & 8 & 21.6 & 4 & 17.4 & 12 & 20.0 \\
\hline $61-70$ & 10 & 27.0 & 8 & 37.8 & 18 & 30.0 \\
\hline $71-80$ & 9 & 24.4 & 5 & 21.7 & 14 & 23.4 \\
\hline
\end{tabular}

Table 4 shows that similar age and sex matched controls were taken for the study as CRP increases with age.

Table 5 : Localization of Lesions on CT Scan $(\mathrm{N}=60)$

\begin{tabular}{|l|l|l|}
\hline & No. of cases & Percentage \\
\hline Cortical & & \\
\hline
\end{tabular}

\begin{tabular}{|l|l|l|}
\hline Frontal & 8 & 13.4 \\
\hline Parietal & 20 & 33.3 \\
\hline Temporal & 2 & 3.3 \\
\hline Parietotemporal & 6 & 10.0 \\
\hline Frontoparietal & 8 & 13.4 \\
\hline Sub cortical & & \\
\hline Basal ganglia, Thalamus & 12 & 20.0 \\
\hline Internalcapsule & 4 & 6.6 \\
\hline
\end{tabular}

Cortical infarction constituted $73.4 \%$ of cases in which maximum cases $(33.3 \%)$ had infarction in the parietal lobe, followed by frontal and fronto-parietal areas which had $13.4 \%$ each. Sub cortical infarction constituted $26.6 \%$ with basal ganglia and / or thalamus involved in $20 \%$ cases

Table 6 : NIH Stroke Scale (N-60)

\begin{tabular}{|c|c|c|c|c|}
\hline \multirow[t]{2}{*}{ NIH Scale } & \multicolumn{2}{|c|}{ No. of patients } & \multicolumn{2}{|c|}{ Total|Percentage } \\
\hline & Male & Female & & \\
\hline Minor Stroke (1-4) & 8 & 2 & 10 & 16.6 \\
\hline Moderate Stroke (5-15) & 18 & 15 & 33 & 55 \\
\hline Moderate - Severe Stroke (16-20) & 10 & 4 & 14 & 23.4 \\
\hline Severe Stroke (>20) & ]1 & 2 & 3 & 5 \\
\hline
\end{tabular}

Table 6 shows Minor stroke accounted for $16.6 \%$ cases, while most patients (both male and female) $55 \%$ had moderate stroke, only $5 \%$ cases had severe stroke, whilst $23.4 \%$ had moderate to severe stroke.

Table 7 : Mortality chart showing sex distribution

\begin{tabular}{|c|c|c|c|c|c|c|}
\hline \multirow[t]{2}{*}{ Risk Factor } & \multicolumn{2}{|c|}{ Known Cases } & \multicolumn{2}{|c|}{ Newly Detected } & \multirow[t]{2}{*}{ Total } & \multirow[t]{2}{*}{ Percentage } \\
\hline & Male & Female & Male & Female & & \\
\hline Diabetes & 2 & 1 & 1 & 1 & 5 & 35.7 \\
\hline Hypertension & 2 & 1 & 0 & 0 & 3 & 21.4 \\
\hline \begin{tabular}{|l|} 
Diabetes + \\
Hypertension
\end{tabular} & 2 & 0 & 2 & 0 & 4 & 28.6 \\
\hline None $(\mathrm{N}=10)$ & 0 & 0 & 0 & 0 & 2 & 14.3 \\
\hline
\end{tabular}

Table 7 shows Total number of deaths in the study were 14 (10 males, 4 females). Diabetic deaths constituted for $35.7 \%$ of the cases of them 3 were males and 2 females. Hypertensive group saw $21.4 \%$ (3) deaths in in total and mortality was seen only in known cases of which 2 were males and one female.

Table 8: C-reactive protein level in CT proved ischaemic stroke patients

\begin{tabular}{|c|c|c|c|c|}
\hline & \multicolumn{4}{|c|}{ C - reactive protein Levels } \\
\cline { 2 - 5 } & $<\mathbf{6 m g}$ / dl & Percentage & $>$ 6mg/dl & Percentage \\
\hline $\begin{array}{c}\text { Study group } \\
(\mathrm{N}=60)\end{array}$ & 6 & 10 & 54 & 90 \\
\hline Control $(\mathrm{N}=60)$ & 53 & 88 & 7 & 12 \\
\hline
\end{tabular}

Table 8 shows CRP values of CT evaluated ischemic stroke patients after admission, $>12$ hours $<72$ hours after the symptoms onset 54 of the 60 thrombotic stroke patients had CRP $>6 \mathrm{mg} / \mathrm{dl}$ only 6 patients had $\mathrm{CRP}<6 \mathrm{mg} / \mathrm{dl}(\mathrm{P}<0.001)$. Chi- square test value was 73.65 , which is statistically very significant. Only 7 patients in the control group had CRP $>6 \mathrm{mg} / \mathrm{dl}$.

$$
\mathrm{X}^{2}=73.65, \mathrm{p}<0.001
$$

Table 9: $C R P$ levels in relation to age $(N=60)$

\begin{tabular}{|c|c|c|c|}
\hline \multirow{2}{*}{ Age in Years } & \multicolumn{2}{|c|}{ CRP Values } & \multirow{2}{*}{ Total } \\
\cline { 2 - 3 } & $>\mathbf{6 m g} / \mathbf{d l}$ & $<\mathbf{6 m g} / \mathbf{d l}$ & \\
\hline $21-30$ & 0 & 0 & 0 \\
\hline $31-40$ & 2 & 2 & 4 \\
\hline $41-50$ & 11 & 1 & 12 \\
\hline $51-60$ & 11 & 1 & 12 \\
\hline $61-70$ & 16 & 2 & 18 \\
\hline $71-80$ & 12 & 2 & 14 \\
\hline
\end{tabular}

Table 9 shows the relation of CRP values with age, i.e. CRP level is more between the age group of $61-70$ and is less in young adults $(<40$ years of age) 
Figure 1 : CRP Levels in Relation to Age $(\mathrm{N}=60)$

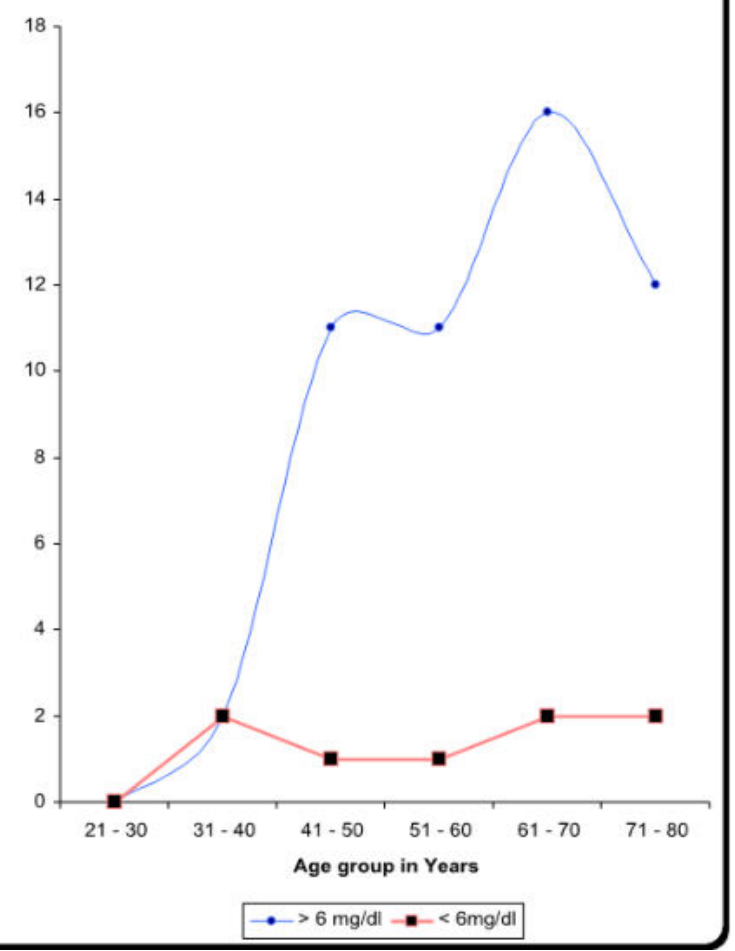

DISCUSSION

Strokes kill »5 million people each year. Cerebrovascular disease is the second cause of death world wide ${ }^{1-2}$

Kristensen $\mathrm{B}^{3}$ et al documented young ischemic strokes occuring in patients younger than 45 years old was rare and less than 5 percent of all cerebral infarctions. A recent stroke registry study by T.Song - Hai $\mathrm{Lee}^{4}$ et al revealed that the incidence of young stroke was $6.8 \%$ of all strokes.In our study young ischemic stroke less than 40 years of age constitutes $6.6 \%$ of all strokes and highest incidence in males was noticed after the age of $61-70$ years i.e. $27 \%$ and in females also the incidence was highest in the age group of $61-70$ years i.e. $37.8 \%$.

The greater prevalence of stroke in men is well known, but recent issues emphasize the importance of stroke in women ${ }^{5}$. Over the entire life time, " $16 \%$ of women but only $8 \%$ of men will die of stroke ${ }^{6}$. Knowledge of sex differences might be of interest in improving preventive strategies and the in-hospital management of stroke patients. Jaume Roquer et $\mathrm{al}^{7}$ documented mean age for stroke was higher in women than in men.In contrast to above studies, we documented the increased incidence of acute thrombotic stroke in both males and females after the age of 60 years with slight predominance in males. We also documented the incidence of thrombotic stroke after 60 years of age in males and females were $73 \%$ and $76.9 \%$ respectively.

Smoking is widely accepted as one of the risk factors for cerebral infarction in western populations. Smoking is thought to affect lacunar infarction mainly through reversible factors, such as increased platelet aggregation and arterial vasoconstriction induced by sympathetic activity rather than through atherogenic factors and this relationship has not been observed in most Japanese epidemiological studies ${ }^{8}$.Contrary to the above study, the above relation of smoking with acute ischemic stroke is not observed in our population.

Manson JE et al ${ }^{9}$ in their study had proved that stroke in diabetics is more likely to be fatal, when compared to anyother novel risk factors.In terms with that of the above study,we also observed that mortality was highest among the diabetic group when compared to hypertensive group or diabetic and hypertensive group.

Thomas S.Bowman et $\mathrm{al}^{10}$ documented that TC, HDL and Triglyceride level were not independent risk factors for ischemic stroke and TC: HDL ratio did not have a linear association with the risk of ischemic stroke.In contrast to the above study we did notice the much significance rise in TC, LDL and TG and decrease in HDL in relation to ischemic stroke when compared to controls in our study.

$\mathrm{CRP}$, one of the acute phase reactants, is an indicator of underlying systemic inflammation ${ }^{10}$ and a novel plasma marker of atherothrombotic disease ${ }^{11,12,13}$. It is likely that CRP has many pathophysiological roles in the inflammatory process,including binding of phosphocholine and recognition of foreign pathogens and phospholipid constituents of damaged cells ${ }^{10}$. Kerstin winbeck et $\mathrm{al}^{14}$ study documents, raised CRP in 127 patients without thrombolysis with a first ischemic stroke no more than 12 hours after symptom onset. In contrast, a CRP increase between 12 and 24 hours after symptom onset predicts an unfavorable outcome and is not a best parameter to predict outcome which is estimated before 12 hours of onset of symptoms.In the present study, CRP was measured only after CT image confirmation of infarction which was done after 24 hours of onset of symptoms. So CRP level was estimated after CT confirmation and before 72 hours of onset of symptoms.In the present study, CRP was elevated in 54 patients out of 60 study group which is statistically significant.

Mario Di Napoli et $\mathrm{al}^{15}$ studied, the risk of CRP in $72 \%$ of patients $(\mathrm{P}<0.0001)$ out of 473 first ever ischemic patients and suggested the $\mathrm{CRP}$ as a independent marker of underlying chronic inflammatory process in atherosclerosis.

Montaner et $\mathrm{al}^{16}$ described a peak level of interleukin- 6 after 24 hours of symptom onset.

Recently, Di Napoli ${ }^{17}$ observed an increase of CRP within 3 hours after stroke compared with the prestroke value.Mahapatra SC et al ${ }^{18}$ observed CRP value $76 \mathrm{mg} / \mathrm{L}$ in 64 patients out of 80 total thrombotic stroke patients $(\mathrm{P}<0.001)$. The study was undertaken to assess the role of inflammation in pathogenesis of ischemic stroke.

Rathore HS et $\mathrm{al}^{19}$ performed a study to measure and compare CRP levels in the cortical and lacunar infarct and to find out their diagnostic importance at an early stage of stroke. CRP was estimated in 25 cases of lacunar and 25 cases of cortical infarct. The CRP was considered positive if its value was more than $6 \mathrm{mg} / \mathrm{L}$, observed rise of CRP in $12 \%$ cases of lacunar infarct and $88 \%$ cases of cortical infarct.In the present study the CRP rise was $82.4 \%$ in cortical and 26.6 in subcortical. It was clearly observed in our study that CRP was raised in all subtypes of cerebral infarct without much difference.

In Irene $\mathrm{M}_{\text {et }} \mathrm{al}^{20}$ study, CRP levels were measured in a random sample of 773 subjects ${ }^{3} 55$ years of age and follow-up was done for the next 6.5 years. They documented the progression of subclinical atherosclerosis and CRP predicts myocardial infarction and stroke.

In our control study involved age and sex matched healthy individuals; the rise of CRP level was noted in $12 \%$ of cases. The prediction of myocardial infarction and stroke couldn't be done since it needs longer follow-up.

In L.Masoti et $\mathrm{a}^{21}$ study they retrospectively measured CRP values in 196 elderly patients for relationship between CRP and short term prognosis and concluded that elevation of CRP could represent a negative prognosis in elderly patients with ischaemic stroke, in particular, for short term prognosis.In the present study, there were 14 deaths, 10 were males and 4 were females and in all of them CRP $>6 \mathrm{mg} / \mathrm{dl}$ which is in terms with that of the above study reiterating that elevated CRP levels were a bad prognostic indicator.

\section{SUMMARY}

Stroke incidence increases with advancing age and is more in males when compared to females Incidence of stroke is more common in diabetics then when compared to hypertensives or patients with both hypertension and diabetes. Fatal stroke was highest among the diabetic group. Non-fatal stroke was common among the hypertensive group. Mortality was highest among moderate stroke group on NIH stroke scale. C-reactive protein is an independent risk predictor for ischemic stroke. $\mathrm{C}$-reactive protein level increases as age advances and has no significant gender predilection, so age and gender predilection of CRP plays no effect on mortality in first ever ischemic stroke patients. C-Reactive protein level has no significant relation to site and size of infarct. C-Reactive level cannot differentiate the subtypes (cortical and sub cortical) of cerebral infarct at the time of early 
diagnosis. C-Reactive protein is a sensitive parameter to predict future myocardial infarction and stroke. In control group about $88 \%$ individuals had no significant rise of CRP.

\section{CONCLUSION}

In this study mean C-Reactive protein levels were significantly higher in patients with ischemic stroke when compared to controls. Creactive protein level increases as age advances and has no significant gender predilection so age and gender predilection of CRP plays no effect on mortality in first ever ischemic stroke patients. It is also observed that by elevated C - Reactive Protein in ischemic stroke can be diagnosed positively but subtypes (cortical, subcortical) of cerebral infarction cannot be differentiated at the time of early diagnosis. C - Reactive Protein levels being raised within 72 hours of an acute ischemic stroke is poor prognostic indicator. C Reactive Protein levels were raised in all cases who expired.

\section{REFERENCES}

1. Murray CJL, Lopez AD. Mortality by cause for eight regions of the world: Global burden of disease study. Lancet 1997; 349: 1269-1276.

2. Murray CJR, Lopez AD. Alternative projections of mortality and disability by cause 1990-2020: Global burden of disease study. Lancet 1997; 349: 1498-1504.

3. Kristensen B et al. Epidemiology and etiology of ischemic stroke in young adults aged 18-44 years in Northern Sweden. Stroke 1997; 28: 1702- 1709.

4. Tsong-Hai Lee et al. Etiologic study of young ischemic stroke in Taiwan. Stroke 2002; 33: 1950-1955.

5. Bousser MG. Stroke in women. Circulation 1999; 99: 463-467.

5. Bousser Stroke in women.

6. Bonita R. Epidemiology of stroke. Lancet 192,339:342-344. Jaume Roquer, Ana Rodriguez Campello, Meritxell Gomis. Sex differences in first-ever
acute stroke. Stroke 2003;34: 1581-1585. acute stroke. Stroke 2003; 34: 1581-1585.

8. Yumihiro Tanizaki et al. Incidence and risk factors of subtypes of cerebral infarction in a general population. The Hisayama Study. Stroke 2000; 31:2616-2622.

9. Manson JE et al. A prospective study of maturity onset diabetes mellitus and risk of CHD and stroke in women. Arch. Intern Med 1991; 151: 1141-7.

10. Gaby C, Kushner I. Acute phase proteins and other systemic responses of inflammation. NEngl J Med 1999; 340: 448-454.

11. Danesh J, Collins R, Appleby P, Peto R. Association of fibrinogen C-RP, albumin or leukocyte count with coronary heart disease. JAMA 1998; 279: 1477-1482.

12. Wilson PWF. Metabolic risk factors for coronary heart disease. Current and future Wilson PWF. Metabolic risk factors for coronary heart disease. Current and future prospects. Curr Opin Cardiol 1999; 14: 176-185.

13. Ridker PM. Evaluating novel cardiovascular risk factors: Can we better predict heart attacks? Ann Intern Med 1999; 130: 933-937.

14. Kerstin Winbeck et al. Prognostic relevance of early serial C-reactive protein measurements after first ischemic stroke. Stroke 2002;33:2459-2464.

15. Mario Di Napoli, Francesca Papa. Inflammation, hemostatic markers and antithrombotic agents in relative to long-term risk of new cardiovascular events in firstever ischemic stroke patients. Stroke 2002;33:1763-1771.

16. Montaner J et al. Correlation between the expression of proinflammatory cytokines and matrix metalloproteinases in the acute phase of an ischemic stroke. Rev Neurol 2001; matrix metalloproteinases in the acute phase of an ischemic stroke. Rev Neurol 2001, 33: $115-118$.

17. Di Napoli M. Early inflammatory response in ischemic stroke. Thromb Res. 2001; 103: 261-264.

18. Mahapatra SC et al. C-reactive protein in thrombotic stroke. JAPI Dec 2002; 50: 1512.

19. Rathore $\mathrm{HS}$ et al. Role of C-reactive protein estimation in early diagnosis of cortical and lacunar infarct. JAPI Dec. 2002; 50: 1516

20. Irene $\mathrm{M}$ et al. C-reactive protein predicts progression of atherosclerosis measured at various sites in the arterial tree. The Rotterdam Study. Stroke 2002;33:2750-2755.

21. L.Masotti et al. Prognostic role of C-reactive protein in very old patients with acute ischaemic stroke. Journal Of Internal Medicine 2005;258:145-152. 